\title{
Los procesos informativo-documentales de la tasación del libro antiguo
}

\author{
Manuel José Pedraza Gracia \\ Universidad de Zaragoza (España)
}

\subsection{Resumen}

Se estudia el proceso de tasación como proceso de tratamiento documental estableciendo las relaciones que se producen entre el libro como documento primario y el informe de tasación o el catálogo como documento secundario.

Palabras clave: Libro antiguo. Libro raro. Librería anticuaria. Casas de subasta. Tasación. Bibliofilia.

\subsection{Abstract}

The book appraisal process is studied as an information treatment process, establishing the relations between the book as a primary document and the appraisal report and the catalogue as secondary documents.

Keywords: Old books. Rare books. Rare materials. Antiquarian bookshops. Auction houses. Appraisal. Bibliophily. Book collectors.

\section{Introducción}

Cuando se trata el tema de la tasación del libro antiguo, la primera pregunta se encamina siempre a resolver la duda sobre la causa que la origina. El problema que se pretende resolver parte de la premisa de que no existe una única respuesta a esta pregunta y que las diferentes respuestas comportan, en la mayoría de los casos, resultados distintos. El objetivo que se persigue con la tasación proporciona precios acordes con él. Para qué se tasa es, pues, la principal pregunta y existen múltiples respuestas: para la compra por parte de un mayorista de un ejemplar, o de un lote o de una biblioteca; para su venta a un coleccionista o institución pública o privada; para establecer un precio que sirva de medida en un canje, para que el objeto tasado sirva como garantía, para el seguro de una exposición, para emitir un informe... En consecuencia, parecería que, más que hablar de la tasación del libro antiguo, se debería tratar de las tasaciones del libro antiguo. No obstante, a no ser que se diga lo contrario, cuando se habla de tasación se habla siempre de la tasación para hallar el precio de mercado, es decir, el precio por 
el que el consumidor final adquiere el documento, de la misma manera que en cualquier otro ámbito comercial. Todo esto no implica que existan otros fines y otros intereses al solicitar un informe de tasación sobre documentos o conjuntos de documentos concretos.

La tasación del libro antiguo se articula esencialmente sobre dos elementos que se relacionan: un objeto - que habrá de entenderse como objeto documental - y una cantidad económica. Tasar un libro antiguo es, por tanto, desde esta perspectiva de la apreciación del común de los observadores, establecer una relación buscando el equilibrio entre estos dos parámetros. Desde esta misma perspectiva, la corrección o incorrección en la tasación se podría llegar a medir con precisión estableciendo la cantidad económica en la que se desequilibra la relación. Por consiguiente, proporcionar una definición sobre tasación de libro antiguo y fijar unos criterios de calidad no resulta difícil, más bien al contrario, como se ha visto. No obstante, si se penetra en cada uno de los dos elementos que se disponen en la balanza llegaremos a apreciar la complejidad de este asunto, ya que en el libro intervienen unos factores internos, que lógicamente inciden en el precio, pero no son los únicos. Efectivamente, existen factores externos al libro que también influyen en la definición de un precio. Estos factores, como se verá más adelante, son factores endógenos del proceso de tasación. Además existen otros exógenos al proceso pero que también influyen en el resultado.

Otro elemento que se debe considerar es el agente. El tasador frecuentemente no es independiente del negocio. Su intervención podría parecer un condicionante del resultado del proceso, lo que, en muchas ocasiones, sirve de freno para considerar una única tasación como válida o aceptable. Frecuentemente se busca la opinión de más de un profesional con objeto de establecer una medida - la media - que se adecue a lo que, en efecto, vale un libro antiguo. La intervención de otros factores de carácter psicológico y los errores cometidos por impericia, descuido o inadvertencia son también causa de la posibilidad de variaciones importantes en el resultado.

Un último factor es el destinatario de la tasación. Éste puede llegar a condicionar en función de sus características el resultado tanto con su actitud como con sus conocimientos. Pero una particularidad del destinatario es que en esencia también él es, en buena medida, tasador, puesto que en muchas ocasiones se debe de replantear cómo se ha efectuado la tasación y que factores pueden haber influido en ella.

Por consiguiente, antes de entrar en el complejo proceso de la tasación de los libros antiguos parece imprescindible analizar estos cinco factores: la finalidad de la tasación, el objeto al que se ha denominado libro antiguo, el precio con el que se relaciona, la persona que emite la tasación y el destinatario de la misma. Se trata 
de observar si se trata de elementos esenciales, endógenos, en el proceso y que, por esa causa, lo condicionan; o simplemente, tienen influencia en el resultado sin condicionar ni intervenir en el proceso, esto es, exógenos.

\section{La finalidad de la tasación}

El principal acontecimiento que conduce a efectuar una tasación de un bien (sea del tipo que sea) es su transmisión. Si se trata de libros antiguos esta transmisión puede responder principalmente a una compraventa directa o a una subasta pública. En muy menor medida, la tasación puede responder a una transmisión mediante canje o a la entrega de fondo bibliográfico a cambio del pago de impuestos o como garantía contra otro bien. También se piden tasaciones en los casos en los que se precisa garantizar la integridad del documento como tal. Por último, existen tasaciones que se solicitan para ayudar a establecer prioridades sujetas a criterios objetivos. Existen, por tanto, muchas y muy diversas finalidades que merecen un análisis pormenorizado.

Los documentos se tasan fundamentalmente para ser vendidos o, mejor aún, cuando son vendidos. El recorrido del libro en la venta directa produce siempre dos o más tasaciones. El libro se tasa cuando el librero lo adquiere (de un particular o de otra librería, de forma individual o inmerso dentro de lotes o bibliotecas); y el libro se tasa de nuevo cuando lo pone a la venta (en oferta). En ocasiones se tasa por tercera vez cuando no se vende (se entiende que no se vende porque existe un sobreprecio) o cuando, en efecto, se vende (con correcciones o descuentos sobre el precio de oferta). El objeto, a no ser que se haya sometido a leves restauraciones o reencuadernación, no cambia en ninguno de los cuatro supuestos vistos; lo que cambia es el precio. Los motivos últimos de estas variaciones, aún siendo evidentes, ocasionan más de un problema, debido especialmente a que el primer vendedor se considera defraudado cuando conoce la cuantía en que se vende al comprador final. Si se analiza esa diferencia, se habrá de considerar que no debería exceder de lo que se considera natural para el mantenimiento de un negocio altamente especializado que precisa de profesionales muy cualificados, sujeto a los mismos desembolsos que cualquier otro: impuestos, gastos fijos, gastos de difusión... De la misma manera que se han visto variaciones cuando se tasa con fines distintos, tampoco se suele tasar de la misma manera cuando se adquiere un libro único o cuando se adquiere un lote o una biblioteca, debido a que el comprador (no el tasador) establece en este caso unos promedios que se justifican unas veces en el rendimiento económico de la inversión y otras en la desconsideración de los ejemplares menos demandados o interesantes. El tasador puede, siendo consciente de que las unidades pierden la opción de un tratamiento más adecuado, tener en cuenta estas circunstancias que pueden pesar en la venta. Pero en este caso se trata de una tasación condicionada.

Scire. $10: 1$ (en.-jun. 2004) 101-120. 
Debido a esa sensación de fraude que se produce en el primer vendedor, éste opta en muchas ocasiones por la subasta. Pero, en una subasta se producen también tres tasaciones la de salida, es decir, el precio mínimo a partir del cual se puede pujar (determinada por el tasador de acuerdo con el vendedor); la estimada, esto es, el precio que puede llegar a alcanzar (determinada exclusivamente por el tasador); y el remate, precio por el que se adquiere (determinado por el comprador). La casa de subastas obtiene un porcentaje fijo sobre el precio de remate, salvo pacto en contrario. También aquí se pueden producir pequeñas modificaciones sobre los precios, condicionadas por el hecho de que una casa de subastas es también un negocio, que, sobre todo, pretenden influir en la psicología del comprador potencial, llevándole a pensar que el libro tiene un precio más barato del precio de mercado o que puede alcanzar un precio más alto en el futuro.

Las tasaciones que se solicitan para el canje y para la compensación de impuestos, al igual que las que se efectúan para propia información o la ayuda a la toma de decisiones, son únicas y se determinan exclusivamente por un tasador, generalmente imparcial o, en otros casos, por un profesional del mundo de la documentación al servicio de las administraciones públicas y, por tanto, alejado del interés de la transacción.

La causa de la tasación condiciona tradicionalmente un aspecto de interés: la tasación comercial se expresa en catálogos de librero o casa de subastas (que tienen un aspecto muy similar). Otras tasaciones, especialmente las que se emiten con el fin de ayudar a la toma de decisiones, se expresan mediante informes. Esta división es mucho más formal que de contenido, ya que ambos tipos contienen prácticamente los mismos elementos, cuya determinación y tratamiento exigen los mismos procedimientos.

En consecuencia puede definirse la causa como un factor exógeno, no solamente al objeto, sino, desde el punto de vista que interesa en este trabajo, también al proceso, aunque de fuerte incidencia en el resultado final; de tal manera, que la causa se transforma en el primer elemento que incide en el precio de manera sustancial y en el medio de manera formal aunque sin modificar el proceso. Pero independientemente de las causas que motiven la tasación del objeto documental, el libro antiguo, protagonista de la tasación, será, sin lugar a dudas, en sí mismo el elemento que se debe considerar necesariamente.

\section{Libro antiguo}

En otro lugar ya se trató este tema de forma profunda poniendo de manifiesto la escasa adecuación del término "libro antiguo" con el objeto documental que se comercia en el mercado del libro antiguo (Pedraza, 2002a, p. 11-14). Pero, este objeto debe ser determinado, a fin de evitar desviaciones sobre el proceso que 
fundamenta. Si existe una certeza en el mundo de la tasación del libro antiguo es que éste no tiene forzosamente que ser ni libro - puede ser perfectamente una publicación seriada, una fotografía, una postal, una estampa, un mapa...- ni antiguo - puede ser un manuscrito contemporáneo o una primera edición de la segunda mitad del siglo XX-. Existen, además, otros conceptos que, en ocasiones se consideran sinónimos, se entiende más próximo al concepto de "fondo antiguo" que se impone en la terminología y bibliografía de la Biblioteconomía, y se confunde con el de "patrimonio bibliográfico y documental", aunque sea un concepto casi exclusivamente jurídico en nuestro medio. En los tres ámbitos se trabaja con objetos documentales y en los tres se tratan documentalmente y se difunden. Sin embargo, salvado lo dicho, cada biblioteca, cada centro, cada institución o particular que posee libros antiguos, independientemente del objeto de su difusión, interpreta como tales conjuntos bibliográfico-documentales no coincidentes, en función de los intereses de sus usuarios y de la finalidad del centro en cuestión. Este problema se acentúa conforme existe mayor proximidad a ese límite difuso que separa el libro antiguo del moderno. En este conjunto de objetos documentales, predominan, en efecto, los libros. Este peso predominante produce que la sinécdoque haya sido completamente aceptada y debamos convivir con ella, como con otras muchas en el mundo de la Documentación. Pero, incluso, cuando se habla de libro es preciso especificar más, hasta llegar a determinar con claridad ese objeto documental que se tasa.

El libro antiguo es el producto de una actividad artesanal muy someramente mecanizada. Este factor, que no siempre se tiene presente, es, de por sí, determinante de la existencia de variantes que se producen en los procesos manuales y mecánicos de producción. En consecuencia, aunque por definición se persiga en su ejecución la reproducción de múltiples ejemplares idénticos, pueden encontrarse sin intervenciones externas al proceso de producción (debido a su propia génesis) diferencias que dotan a un conjunto de ejemplares de la edición de características especiales. Cuando intervienen esos agentes externos se incrementan exponencialmente las posibles variaciones dando como resultado ejemplares cuya única relación entre sí es el origen.

El libro antiguo no es un objeto que se haya encontrado aislado durante el transcurso del tiempo, como ocurre con un objeto arqueológico escondido en un estrato o un objeto artístico custodiado en un museo: es un objeto vivido. En esa vida el objeto se ha relacionado con su entorno. En cierta medida, se ha contaminado, desde la perspectiva de la pureza (lo que los anglosajones denominan "genuinidad"). Esta relación ha podido influir de forma positiva o de forma negativa en el objeto. Pero, en cualquier caso, no se puede olvidar que el uso del libro implica siempre una degradación del mismo, un desgaste; y que no puede ser usado, por tanto, sin ser agredido. Es precisamente el juego entre agresión (sea

Scire. $10: 1$ (en.-jun. 2004) 101-120. 
del tipo que sea) y protección contra la agresión una de las particularidades que produce el efecto de individualización extrema en el libro antiguo. Existen, por tanto, diversas facetas que lo enriquecen por adición. El libro, con el transcurso de su existencia, se ve sujeto a múltiples avatares que paulatinamente hacen que un ejemplar se vaya diferenciando de otro. Por esta causa, es prácticamente imposible encontrar dos ejemplares idénticos. Todos estos factores condicionan en una o en otra medida y en una o en otra dirección el precio del ejemplar. Por esta causa, se puede hablar de la existencia de factores positivos y factores negativos. El precio de un ejemplar de una edición es un buen referente del precio de otro ejemplar de la misma edición, pero no es determinante. La pertenencia a una misma edición de dos ejemplares no significa que sean idénticos, ya que pueden pertenecer a variantes distintas. El libro se transforma, así, en un objeto de una riqueza de matices enorme que tienen su origen en el conglomerado de elementos de toda índole que lo constituyen. Pero precisamente esta variedad de elementos es la responsable del atractivo del libro y de los impresos antiguos trasformándolos en documentos singulares, ya sea por su propia génesis o ya sea por el efecto del transcurso del tiempo. Es preciso valorar, además, de forma objetiva el cúmulo de características que diferencian los ejemplares originalmente idénticos entre sí. De esta manera, un ejemplar en perfecto estado es más caro siempre que un ejemplar con algún tipo de deficiencia; y, viceversa, cuanto mayor sea ésta, más barato podrá adquirirse. Incide aquí el concepto de rareza (Olaechea, 1987); pues los ejemplares en perfecto estado son más raros que los ejemplares con alguna deficiencia. Este cúmulo de avatares que se ha citado tiene mayor probabilidad de afectar al libro cuanto más antiguo sea éste. En consecuencia, un libro antiguo en perfectas condiciones resulta ser aún más raro, más buscado y, sobre todo, más caro. Todavía más evidentes son estas apreciaciones cuando se trata de ejemplares únicos, como ocurre siempre con los manuscritos, a pesar de lo cual, todavía se pueden encontrar condiciones como la de autógrafo o inédito que intervienen el precio de forma positiva frente a las de copia o publicado.

Entre los factores externos o propios del ejemplar se destacan a continuación los que pueden considerarse de más importancia: la antigüedad en el libro, rareza, estado de conservación general - el guillotinado de los cortes, el ataque de insectos, el desgaste por el uso, la influencia del medio físico...-, ciertas particularidades - textos adjuntados, manipulaciones, la encuadernación, el encartado de hojas en blanco...-, anotaciones, procedencia (exlibris, superlibris, exdonos, dedicatorias...), y las mutilaciones.

Los factores internos al libro u originales de la edición o variante que inciden en el libro pueden ser de dos tipos los que tienen que ver con la materialidad del libro (el objeto) y los que tienen que ver con la obra (el contenido del objeto). Entre los primeros destacan el origen material, el cuidado tipográfico, la ilustra- 
ción del libro, la encuadernación, la calidad del papel y la variante. Por último, el contenido de la obra es uno de los aspectos fundamentales de este libro buscado por los bibliófilos. El contenido se puede medir desde dos vertientes: la obra que el libro contiene (autor, título o colección), y la materia de la que versa el libro.

Bien es cierto que no todos estos factores influyen de la misma manera ni deben darse conjuntamente, ni son los únicos. Pero todos ellos están sujetos, además, a las modas. Muchas de estas características no son excluyentes pero otros factores pueden influir en muy menor medida y no despertar el mínimo interés. Todo ello conduce a un hecho que se pone de manifiesto por comparación: No se puede establecer una relación unívoca entre una edición de una obra y un precio. Si esto fuese así, la tasación devendría en un mero incremento del precio originalmente asignado según factores meramente económicos.

En el libro antiguo encontramos unos factores internos que tienen que ver con las características propias de la edición o variante y que la individualizan del resto de las ediciones y variantes, que podemos definir como factores originales. Además, existen unas características con las que se ha dotado o que han afectado al ejemplar en el transcurso de su historia y que lo individualizan dentro de los de su misma edición o variante, que podemos definir como factores propios. Estos factores son capitales a la hora de determinar el precio del libro hasta el punto que no pueden omitirse. Son estos elementos los que condicionan el precio y lo explican. No se puede suponer - aunque en el mercado del libro antiguo no es infrecuente - que el receptor de la información tenga un conocimiento profundo del ejemplar: el ejemplar condiciona el precio y, por tanto, éste debe justificarse con las características propias de aquél. Tanto los factores originales como los propios actúan como factores endógenos en el proceso de tasación siendo su análisis consustancial al mismo.

\section{El precio}

Un precio no implica siempre una relación comercial, de la misma manera que una relación comercial no exige siempre un precio. El precio de un objeto o servicio también posee un valor informativo de primera magnitud para la toma de decisiones: de adquisición, de venta, de custodia, de prioridad, de garantía, de mutación, de reparación... Pero no se puede confundir precio con valor. El valor de un objeto se establece de forma objetiva en función de su importancia o trascendencia para el ámbito o ámbitos a los que hace referencia. El valor se encuentra en el lugar diametralmente opuesto al precio. Se puede hablar de valor histórico, científico, literario, cultural, etnológico, artístico, religioso, informativo...; esto es, la determinación de la importancia que ese objeto posee con respecto a otros objetos dentro un ámbito específico. Hay que tener en cuenta, además, que estos ámbitos no son excluyentes: un libro puede tener valor histórico, literario

Scire. $10: 1$ (en.-jun. 2004) 101-120. 
y artístico al mismo tiempo. El precio, por tanto, podría definirse, en este nivel teórico, como la traducción económica del valor. En efecto, el valor, o los valores, y las circunstancias que influyen en ellos inciden en el precio; pero no siempre, ya que valor y precio no son, a pesar de lo dicho, magnitudes equiparables. El valor de un libro está determinado por múltiples factores que van desde el ámbito de lo íntimo o afectivo, que hacen que alcance para una persona un valor excepcional, hasta el ámbito del conocimiento universal, el estético, el histórico...

La norma que predomina cuando se trata de precios es la ley de la oferta y la demanda. La demanda y la oferta de ejemplares con características o contenidos similares es un ingrediente determinante en el precio. Cabe preguntarse qué mecanismos condicionan la oferta y la demanda. Si se profundiza en este campo se llega a la conclusión de que entre los elementos que sustentan la demanda se encuentran algunos de índole extremadamente diversa: la moda, los avatares históricos o sociales, la sobrevaloración o minusvaloración de la calidad de determinados productos, algunos fenómenos coyunturales, la competencia entre bibliófilos o entre instituciones, el componente mitológico, el valor... Los ejemplares perfectos son más buscados por los bibliófilos que los ejemplares con deficiencias por muy pequeñas que éstas sean; aunque en determinado momento, cuando el precio incide de forma firme en el descenso de la demanda, tienden a equipararse. En muchas colecciones prevalece el criterio de calidad de los ejemplares por encima del criterio de cantidad, ya que actúa como principio general. La oferta también se ve condicionada por diversos elementos, entre los que tienen un peso excepcional la venta de bibliotecas de calidad - primordialmente cuando se trata de colecciones con un grado alto de especialización-e, incluso, las coyunturas económicas desfavorables. En un nivel práctico, el precio del libro antiguo ha sido definido, siguiendo premisas similares a las anteriores, como la cantidad económica máxima que alguien está dispuesto a pagar por él (Clavería, 2002; 173). Existen otros precios, empero. Algunos de ellos se han apuntado en párrafos anteriores y otros requieren una consideración más detallada.

El precio al que un mayorista adquiere un libro, lógicamente ha de ser menor que el precio de mercado, o de lo contrario, no vendería el producto adquirido, inmovilizaría mucho líquido y no podría hacer frente a otras adquisiciones. El mayorista proporciona un valor añadido al libro, mantiene un negocio y una cartera de clientes a quienes asesora y, sobre todo, reúne un material que, de otra manera, por disperso, resultaría inaccesible. La reunión de elementos comunes favorece su relación y comparación y, por tanto el establecimiento de prioridades. El precio por el que se adquiere un lote o una biblioteca no es el resultado de la suma de los precios de las unidades que lo componen. La coherencia en su composición puede producir la desviación en ambas direcciones. Un conjunto coherente que puede transmitirse íntegro gana valor y precio. Un conjunto esca- 
samente coherente del que se han extraído las unidades que individualmente tienen una venta más fácil y adquieren mayor precio, pierde valor. En la compra de libros por parte del librero, el precio del libro es el que éste está dispuesto a pagar por un libro y que lógicamente es menor que el precio que pagaría el coleccionista. Oscila notablemente con respecto al precio al por menor. Cuando se quiere obtener líquido el precio del libro depende esencialmente del tiempo que se esté dispuesto a esperar para obtener la cantidad en líquido.

Con todo, el precio de oferta puede no coincidir con el de mercado ya que al final se puede proceder a ajustes, bien sea mediante la aplicación de descuentos a clientes o bien sea por aceptar una contraoferta de los mismos. Pero hay que tener en cuenta que encontrar al coleccionista pertinente para un libro específico puede no ser fácil y que las desviaciones juegan siempre en contra del vendedor.

El precio de salida en una subasta puede definirse como el precio mínimo que se puede aplicar al objeto concreto que se subasta. Este precio suele obtenerse mediante el acuerdo entre el tasador de la casa de subastas y el vendedor. Pero nada impide que este precio se pacte especialmente bajo con objeto de atraer más posibles compradores con un precio especialmente tentador. Lo mismo ocurre con el precio estimado. Este precio, a diferencia de los otros mencionados, no es único y suele fijarse mediante una horquilla. Si el nivel de esta horquilla es alto comparado con el de salida, se constituye como un poderoso atractivo para los compradores.

El precio que se establece para un libro que se lleva a una exposición debería aproximarse bastante al precio de mercado. Generalmente este precio es asignado por un profesional que tiene a su cargo el libro en cuestión. Sin embargo, existen matices que se deben considerar: El precio de un libro que frecuentemente sale en el comercio, ¿es el mismo que el de aquél que sólo sale en raras ocasiones?; el precio de un libro que se expone en un lugar con fuertes garantías de seguridad, ¿es el mismo que cuando éstas se encuentran más atenuadas? Y, por último, el precio establecido para un libro no está condicionado por el precio en el que ha podido ser adquirido. No puede ser lo mismo tasar para un seguro, cuyo objeto es poder recuperar otro ejemplar en similares condiciones en caso de pérdida, que para la compra de una biblioteca. Una tasación para un seguro, para una donación o para una casa de empeños requiere valoraciones justificadas, avaladas $\mathrm{y}$, especialmente, desinteresadas. No obstante, parece evidente que un libro que se adquiere en un precio por debajo o superior al de mercado se verá influido a la hora de ser tasado para un seguro por aquél. Estos matices existen y suelen o deben ser considerados.

En otros procesos de tasación se busca un precio por el que una transacción diferente de la compraventa puede realizarse, como un canje o el pago de impuestos. El precio en este caso suele ser aplicado a lotes, y se suele partir de la base

Scire. $10: 1$ (en.-jun. 2004) 101-120. 
de que existe un riesgo muy minorizado de adecuación del precio al precio de mercado, ya que en la confluencia total con éste se preferiría adquirir las obras directamente. Algo similar ocurre cuando se trata de precios proporcionados para la toma de decisiones. Estos precios se aproximan al precio de mercado, pero se conviene que son los precios por los que se adquirirían los ejemplares tasados. En cualquiera de los casos, siempre que no se produce la adquisición mediante compra se habrá de tener presente que se trata de precios aproximados al de mercado, entendido como aquél al que se aproximan los precios establecidos.

El precio está influenciado, como puede apreciarse, por factores externos al libro antiguo. La oferta y la demanda influyen de manera principal en el llamado precio de mercado, pero éstas están condicionadas por aspectos como las modas, las circunstancias sociales, históricas... Además del precio de mercado existen otros precios en los que influyen siempre características externas al libro. Las circunstancias que intervienen en el valor del libro generalmente inciden en su precio, pero es preciso hacer constar que valor y precio no siempre son magnitudes equiparables. Establecer el equilibrio entre ambos es propio de profesionales especializados. En conclusión, el precio es uno de los componentes esenciales de la tasación y, en cierta medida, el responsable del proceso.

\section{El tasador}

La cantidad económica en la que se tasa el libro es el resultado siempre de la decisión de un individuo: el tasador. El tasador debe tener en cuenta una serie de factores que inciden en el precio, muchos de los cuales son inherentes al libro y otros son independientes de él. Pero uno de éstos, de gran influencia, es el propio tasador. Y es que, aunque el tasador busca siempre la objetividad en su intervención, la absoluta objetividad es simplemente imposible. La tasación tiene un componente de apreciación subjetiva como cualquier otro análisis histórico complejo. Factores de gusto, anímicos, psicológicos, ideológicos y otros de muy diversa índole intervienen en la decisión del tasador. Por consiguiente, resulta imposible que dos tasadores coincidan plenamente en la tasación de un libro antiguo. Esto no implica la existencia de errores: En todos los casos la variación habrá de ser escasa. Existe en la tasación cierta línea gruesa (una banda de precios) en la que se hallarían la mayor parte de las tasaciones obtenidas sobre un objeto; y un número variable de líneas finas, los matices, que establecerían precisamente eso, diferencias de matiz.

Pero quizás la doble intervención del tasador en el proceso como tasador y como comprador o vendedor sea el hecho que, eliminado el error, más influya en el resultado. Esta influencia en el precio no se produce necesariamente de forma consciente e, incluso, no tiene que producirse de forma real; pero introduce un elemento de desconfianza que conduce a cierto nivel de insatisfacción y a la peti- 
ción de segundas opiniones. Resulta manifiesto que, cuando la operación de tasar es efectuada por el propietario del objeto, éste establece una relación entre un conjunto de factores - objetivos y también subjetivos - y una cantidad económica. Cuando esta actividad se realiza para un tercero - como el propietario del objeto tasado- es preciso justificar esos factores apoyándose en los de carácter objetivo a la par que se debe reducir al máximo el peso de los subjetivos. Además, hay que considerar también la posibilidad de errores. El error de tasación puede producirse por una carencia de preparación, de conocimiento del libro por parte del tasador o por un error aislado en un caso concreto en el que ha pasado desapercibido un aspecto específico que modifica la tasación completa - por ejemplo, la reproducción facsímil de una página, la ausencia de una lámina encartada, la identificación incorrecta de cualquier elemento...-. Errores de este tipo pueden producirse en la tasación y en cualquier otro aspecto de la vida.

Como puede verse, el tasador es otro factor exógeno que puede influir de manera sustancial en resultado. Es evidente que esta influencia en el resultado no se produce por una intervención en el método o en el proceso. salvo error. Una tasación bien hecha - esto es, sin errores, al menos en lo que se refiere a sus "trazos gruesos" - no debe diferir de otra y el proceso como tal será el mismo.

\section{El destinatario de la tasación}

Existe una variedad importante entre los destinatarios últimos de una tasación. Cuando la tasación tiene una repercusión pública, el destinatario puede ser cualquiera al que llegue esa tasación, pero entre ese conglomerados de destinatarios se encuentra siempre uno último, el comprador. No es el único, como se ve, ya que también son destinatarios últimos el primer vendedor que acude a un comerciante para que le tase un libro que éste le va a comprar, la compañía de seguros que garantiza la integridad de los documentos de una exposición, el receptor de un informe de tasación para tomar una decisión...

El destinatario puede llegar a condicionar en función de sus características el resultado, puesto que también ejerce cierta presión sobre quien ofrece el libro. Su nivel de conocimientos sobre el libro, su poder adquisitivo o el poder de quien representa pueden producir un abaratamiento o encarecimiento del producto, bien sea porque se teme errar o porque se pretende fidelizar a un cliente. El destinatario puede llegar a ser responsable del proceso cuando modifica el resultado efectuando él mismo la labor de tasación. De hecho el comprador experto no hace sino reproducir el proceso de tasación a efectos de contrastar que el trabajo realizado por el tasador es correcto. Cuando hace notar un error que condiciona la tasación o una distorsión del precio, él mismo se transforma en tasador y, por consiguiente, en protagonista del proceso. Utiliza, sin modificación, los mismos métodos que utilizó el tasador para rebatir la conclusión.

Scire. $10: 1$ (en.-jun. 2004) 101-120. 
El coleccionista gusta de poseer aquellos ejemplares más deseados por otros, lo que conduce a que crezca una determinada demanda sobre ejemplares o tipo de ejemplares muy concretos. En determinados casos, se produce un curiosos fenómeno: El coleccionista busca, más que una obra concreta, suplir una ausencia o una carencia, lo que conduce a una competencia que influye en el precio, pero desde fuera del objeto. Sin embargo, también estas actuaciones son extrañas al proceso. Así, por ejemplo, el destinatario que pretende una información para la toma de decisiones no suele exigir una información concreta sobre el precio, sino, más bien, aproximada; diferente, en suma, de otras tasaciones originadas por causas distintas, pero cuya obtención y referentes se someten al mismo proceso. Estas demandas e intervenciones se producen sobre el mercado o sobre el resultado interfiriendo en el precio, pero no sobre el proceso. El proceso no se ve modificado por parte del destinatario por muy protagonista que sea de él. El destinatario considerado como elemento de intervención en la tasación es, por consiguiente, también un factor exógeno.

\section{El proceso de tasación}

Como se ha visto, la finalidad de la tasación es independiente del proceso. Sea cual sea la causa, el proceso que se realiza para tasar un único documento es idéntico. Por tanto, condiciona el precio, pero no el proceso. Tampoco el tasador condiciona el proceso; pues, independientemente de la persona que lleve a cabo el proceso, éste deberá ser el mismo, aunque, como se ha visto, su actuación puede condicionar el precio. Algo similar ocurre con el destinatario, que puede llegar a condicionar el precio y ser él mismo protagonista principal del proceso, pero no lo modifica. El proceso de tasación se encuentra condicionado por el objeto, ya que sufre pequeñas variaciones cuando, en lugar de tasar un documento único, se procede a tasar lotes o bibliotecas enteras. Por último, el precio tampoco es independiente del proceso, ya que termina por ser el resultado del mismo.

El problema de la interferencia o no de algunos de estos elementos estriba en que se tiende a confundir tasación con precio. Sólo una parte de los elementos que intervienen en la inestabilidad del precio del libro antiguo derivan del proceso de tasación. La tasación habrá de ser única y objetiva para cada uno de los objetos en función de su fin; si no, realmente, el mundo de la tasación se inscribiría en los ámbitos de la arbitrariedad, bien alejada, por tanto de los del comercio. Por ello, la tasación, su proceso, exige un análisis más profundo de las tonalidades que constituyen el objeto complejo que se denomina libro antiguo. Desde una perspectiva informacional pura el tasador emite una información, entre la que figura el precio que un receptor precisa. Esta perspectiva favorece que se pueda considerar el precio como información: una información que permite establecer una comparación con otros objetos de la misma o de distinta clase de cara a la toma de decisiones. 


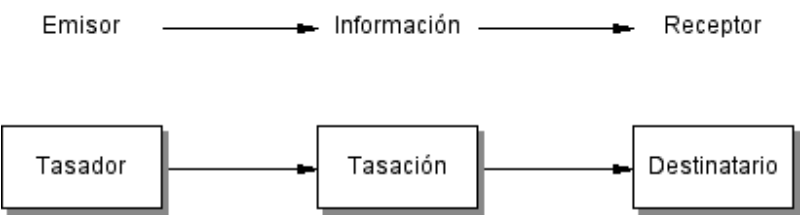

Fig. 1. La tasación como proceso de información

Además, el valor informativo de un precio es universal, ya que no es preciso ser un experto en la materia para interpretar esa información. El precio representa, en este caso, un objeto documental en una escala de valores (económica) perfectamente interpretable por cualquiera y que, como se ha dicho, puede ubicar ese objeto en una escala en la que puede concurrir con otros objetos del mismo tipo o completamente distinto. El precio transforma la comprensión de un objeto estructuralmente complejo y de muchas facetas en algo perfectamente asequible, a la par que favorece su medida. Pero también permite la cuantificación, la medición, en suma, de características diferentes. En consecuencia, se tasa para obtener una información que ayude a la toma de decisiones, ya que el precio es la única información cuantificada que se puede obtener como representación global de un objeto documental. No obstante, el precio en sí mismo, aunque posea este valor, no basta y debe ser justificado. Esta justificación no puede ser independiente del proceso de tasación. Antes bien, es consustancial al mismo, no sólo porque justifica el precio dado, sino porque introduce los elementos distintivos que hacen de ese ejemplar el único que lo posee, ponen de manifiesto cualquier error involuntario y evalúan, también mediante su cuantificación, sus características propias del documento.

Tasar, por tanto, no es únicamente poner precio a un objeto; es también establecer las características que hacen de ese objeto merecedor de ese precio. En consecuencia, es preciso analizar el libro antiguo que se tasa, esos factores internos que hacen del ejemplar algo único y merecedor del precio con el que se ha tasado. En suma, una tasación supone también la evaluación mediante criterios objetivos de objetos documentales. Para tasar un documento hay que obrar mediante un procedimiento, seguir una secuencia de actuaciones, cuyos pasos se analizan a continuación.

\subsection{Identificación}

En primer lugar es preciso identificar el objeto. Por consiguiente, es primordial la determinación de los elementos esenciales del libro antiguo, y su estructuración, con objeto de poder ser comparados posteriormente con los repertorios de libros, las bibliografías. 
Por tanto, la tasación del libro antiguo - que parecía en un primer momento una operación muy elemental -, no lo es tanto debido a esta multiplicidad de factores, y se conforma como un proceso constituido por un conjunto de actuaciones. La primera de ellas, según se ha visto, es la identificación del objeto, su análisis, para extraer de él los elementos que han de servir de factores endógenos de la tasación. La identificación es el primer paso, ineludible, para la tasación, ya que difícilmente se puede establecer el precio de un objeto sin llegar a individualizarlo entre el resto de los de su clase. La identificación de un objeto con tantas facetas y aspectos no puede producirse sin cierta complejidad. Esta afirmación, que puede parecer obvia, se sustenta en la exigencia de la identificación de todos los aspectos que afectan al manuscrito e impreso antiguo, dando lugar a distintos niveles de identificación que pueden dividirse en tres estados: 1) la identificación del grado de integridad documental; 2) la identificación sustancial, característica y singular; 3) la identificación formal y material. La identificación - o la suma de las identificaciones - se articula como una parte sustancial del proceso de tasación, resultando ser el primero de los pasos y el determinante en la corrección del proceso. Los errores identificativos se transfieren siempre al resultado final, la tasación, y la incorrecta tasación influye siempre de forma negativa en la actuación que la ha propiciado.

La identificación del grado de integridad documental es el primer esfuerzo que se ha de realizar en la identificación. En el caso de ausencia de integridad, la comercialización - concretamente, la asignación de precio- del libro se relaciona de forma directa con el impreciso concepto de rareza. Pero, en una tasación de tipo patrimonial o evaluativa se habrá de poner en relación también con determinados aspectos subjetivos.

Posteriormente o de forma simultánea se ha de proceder a la identificación sustancial. Por identificación sustancial puede entenderse la obtención de información de la obra que contiene el libro. Ésta se articula mediante el correcto reconocimiento de dos elementos principales - el título y el autor- y, subsidiariamente, del contenido o materia. Se trata de una información que ofrece el propio documento en la mayoría de los casos, pero no se debe olvidar que esta identificación sustancial se puede convertir en una actividad extremadamente compleja. La ausencia sistemática de datos la dificulta notablemente, como ocurre, por ejemplo, en los primeros incunables, carentes de portada y aún de colofón. Los mútilos y los manuscritos (especialmente las colecciones de manuscritos), pueden ser excelentes ejemplos de esta dificultad. Estos ejemplos pueden ser suficientes, pero, sobre todo, existe un grupo muy heterogéneo de impresos cuya identificación sustancial resulta notablemente compleja: los efímeros.

Por identificación característica se ha de entender el conjunto de información que se puede obtener sobre la confección del libro. Se articula en dos direc-

Scire. $10: 1$ (en.-jun. 2004) 101-120. 
ciones: por una parte, el reconocimiento de los responsables de esa confección y el momento en el que el documento se ha fabricado; y, por otra, la delimitación de la edición y variante a la que pueda pertenecer el ejemplar. Parte de estos datos suelen ser ofrecidos por el propio documento: lugar de impresión, impresor, fecha, editor; otros, como son la identificación de la variante y aún la edición, suelen requerir análisis específicos. Se trata esencialmente de un esfuerzo de investigación que se centra de forma especial en la comparación del ejemplar con otros ejemplares existentes de idéntica procedencia.

Por identificación singular se puede entender la individualización de todos aquellos aspectos que solamente son concernientes al ejemplar, independientemente del momento en el que fueron incorporados al mismo. Ejemplos de estos elementos pueden encontrarse muchos: exlibris, encuadernaciones, intercalado de ilustraciones o de folios en blanco para apuntes, anotaciones manuscritas...

Un tercer y último nivel en la identificación es el que diferencia entre identificación formal e identificación material. Se trata normalmente del último de los niveles identificativos, pero permite avalar o refutar los resultados del análisis realizado para la identificación característica. El tipo de análisis que se requiere suele ser más propio del bibliólogo que del mundo del comercio del libro o de la biblioteca. No obstante, si existen estudios realizados previamente se pueden y deben de utilizar en la identificación para la tasación. Por identificación formal se ha de entender el resultado del análisis de los elementos constitutivos del libro como conjunto de contenidos intelectuales y artísticos. La identificación material, por su parte, es el resultado del análisis del conjunto de elementos constitutivos del libro como objeto físico.

Como puede apreciarse, la identificación de libros e impresos antiguos, no puede quedarse sólo en el nivel superficial, debe descender hasta los elementos constitutivos del libro de tal manera que sus singularidades queden de manifiesto y puedan ponerse en valor de forma positiva o negativa. No se trata, por tanto, solamente de identificar una obra, un autor y una edición, ya que toda esa variedad de elementos, de aspectos que intervienen en el libro, concediéndole mayor o menor valor - documental, histórico, artístico...- precisan ser identificados. Este primer contacto consigue identificar la obra, mediante sus elementos esenciales: autor y título, los datos relativos a la fabricación del libro - lugar de impresión, nombre del impresor y fecha- y la edición; así como otras características propias de la edición específica a la que pertenece el ejemplar: presencia o ausencia de ilustraciones, existencia de preliminares (especialmente de carácter literario), formato, colación, tipografía, lengua... Especiales problemas presentan los manuscritos a la hora de ser identificados, ya que no solamente se ha de identificar la obra que contiene, sino también la versión textual, y si se trata de un texto inédito, si es una copia y otros muchos factores (Dexeus, 1993, 338-340).

Scire. $10: 1$ (en.-jun. 2004) 101-120. 


\subsection{Descripción}

El paso siguiente es la confección de una representación que permita la comparación del documento en cuestión con otros. En este sentido se produce una doble actuación. En primer lugar, se extrae información y se efectúa un análisis de los elementos constitutivos del documento; se trata de un proceso analítico. En segundo lugar, es preciso producir una representación que plasme el resultado del análisis de forma fácilmente comprensible; y, por lo tanto, se trata de un proceso sintético, que se ha de plasmar en un documento secundario, ya que no es otra cosa que una representación del documento primario. La selección de esos elementos y su estructuración posterior da origen a diversos tipos y a distintos niveles de descripción. Como es sabido, cualquier descripción se fundamenta en un doble plano. En primer lugar es preciso establecer los aspectos o elementos que interesan del objeto con el fin de individualizarlo; y, en segundo lugar, la estructura en la que se han de mostrar esos aspectos o elementos. Ambos planos se encuentran condicionados por el fin que se persigue. Ahora bien, la función básica de la descripción bibliográfica es proporcionar suficiente información para poder identificar el libro descrito, entender la impresión y reconocer los contenidos. El propósito de la descripción bibliográfica fue expuesto por Bowers (2001, p. 22) mediante una fórmula tripartita: "proporcionar el registro detallado, analítico, de las características físicas del libro"; "ofrecer una investigación analítica y una disposición ordenada de esas características físicas"; y "acercarse a la historia literaria y tipográfica a través de la investigación y registro de los detalles más adecuados en una serie de libros relacionados entre sî́.

El tratamiento del documento es, pues, un proceso múltiple, que, en esencia, se detiene en la identificación de los elementos relevantes de los documentos para (re)construir con ellos un reflejo sustancial del documento, distinto de éste, que lo identifica y lo individualiza. Sin embargo, en el mundo del comercio del libro, el interés radica en el ejemplar específico que se posee. El interés que se tiene en el libro antiguo es doble y el contenido del mismo no es lo principal; es más, según ha puesto de manifiesto Rossi (1994, p. 17), suele tener más interés "el ejemplar por sus propias características, adquiridas durante su propia historia, que por ser el representante de un núcleo homogéneo, de una serie definida lógica e históricamente, esto es, de una edición." En la descripción que se efectúa para la tasación en los catálogos de librería anticuaria, en los de la casa de subastas y en los de los informes de tasación, el objeto es difundir las características del ejemplar que se pone a la venta o se tasa poniendo de manifiesto especialmente aquéllas que hacen del libro un objeto atractivo o merecedor del precio aplicado. Se resaltan, en definitiva, aquellas características que hacen que el ejemplar, la edición o la obra sean apreciadas por los bibliófilos y las instituciones.

Scire. $10: 1$ (en.-jun. 2004) 101-120. 
Se encuentra precisamente en este punto el elemento desequilibrante entre la descripción bibliográfica - que siempre presenta información relativa al conjunto constituido por una variante o edición, reflejando precisamente lo que le es común - y la tasación - que siempre presenta información relativa a un ejemplar individualizándolo del resto de los ejemplares aún dentro de la misma variante o edición-. Pero no se puede olvidar que la descripción tiene la doble función de mostrar una representación del documento y de establecer comparaciones con otros. Es este doble valor informativo el que la hace imprescindible en el catálogo y en el informe de tasación.

\subsection{Análisis bibliográfico}

La identificación de cualquier objeto se sustenta en la comparación de los elementos esenciales del mismo con los recopilados en los repertorios de objetos similares. Por ello, una vez identificado y descrito se ha de expresar la información que se posee sobre el ejemplar y sobre la edición que ha resultado de la comparación con los repertorios existentes y su localización en ellos. Se torna preciso, por tanto, un conocimiento ciertamente profundo de los repertorios, que se trasforman de esta forma en instrumentos para la identificación. Los instrumentos que se poseen para identificar el libro antiguo y averiguar su rareza y características son muy numerosos, pero perfectamente conocidos por los profesionales de la documentación. A todo esto se debe añadir la potencialidad de la que ha hecho gala la red Internet para el mundo de la recuperación de información. Siempre sin perjuicio de la potencialidad cooperativa que la red ofrece a la hora de construir, actualizar, adicionar... instrumentos de recuperación de información y documentos, como ya se dijo en otro lugar (Pedraza, 1999, 75-89).

Estas herramientas han de permitir identificar el objeto partiendo de los elementos conocidos, los que proporciona la inspección ocular de la obra. Pero, muchas veces, el problema no es tanto el de la existencia de las herramientas precisas para identificar, cuanto el del objeto de esa identificación.

El análisis bibliográfico encuadra el ejemplar en el conjunto al que pertenece, encajándolo dentro de la tradición bibliográfica en un grupo ya reconocido por las recopilaciones bibliográficas aceptadas. El análisis bibliográfico se encamina a avalar por medio de los repertorios bibliográficos y las fuentes de referencia todos los elementos mencionados en la descripción. Por lo tanto, se citarán las fuentes especializadas en las que se proporcione una valoración de la obra o del autor - referencias de autoridad -; los repertorios generales y especializados en los que figure la edición - identificación de la edición-, los repertorios tipológicos de las características específicas que afecten al ejemplar - identificación de exlibris, encuadernaciones, ilustraciones...-; y, si es preciso, por un análisis material del ejemplar. No se pueden rechazar tampoco aquellas fuentes que ya

Scire. $10: 1$ (en.-jun. 2004) 101-120. 
incluyan precios sobre ejemplares de similares origen y características, y que permiten también avalar la decisión tomada sobre el precio.

\subsection{Mención del precio}

El elemento esencial en la tasación es la indicación o mención del precio. Se señalarán también precios de venta de librería anticuaria y remates de subastas de otros ejemplares en venta lo más recientes posibles, indicando la librería o la casa de subasta y la fecha en la que se realizó la transacción.

Como ya se ha visto, se puede hablar, más que de precio, de precios; intentando diferenciar entre precio de comercio, aquél en el que se efectúan las transacciones entre mayoristas o por el que éstos adquieren el libro, y el precio de mercado. Desde esta perspectiva, la tasación correcta en un informe para el uso en la administración es aquella que proporciona el precio de mercado que tendería a ser el último, es decir, aquél por el que el coleccionista o el bibliófilo lo adquiere. Pero, este precio es, sobre todo, el último, el más elevado y, por tanto, el que interesa a todos: al que vende y al que quiere comprar. Es, también, la medida que permite comparar, establecer prioridades y definir actuaciones. Además, es el precio con el que el Estado suele acceder a los ejemplares que le interesan.

Según se trate, el precio puede proporcionarse con concreción o mediante la determinación de una banda entre la que se puede mover, en todo caso, dependerá del objetivo.

\section{Conclusiones}

El resultado del proceso es un documento que se integra en el catálogo de la librería o casa de subastas o que conforma un informe de tasación, en suma un intermediario entre el objeto y el destinatario. Las diferencias entre el catálogo $\mathrm{y}$ el informe son meramente formales y de destinatario. En efecto, se trata de un documento secundario que representa la unidad documental a la que hace referencia indicando sus características generales y las específicas, ubicándolo entre otros y asignándole un precio por sus características propias.

Sobre el libro antiguo se efectúa un proceso técnico, que se puede denominar proceso de tasación. El proceso de tasación tiene como resultado dos tipos de productos informativos: las tasaciones, que, si es preciso, pueden acumularse en catálogos de librería o casa de subastas; y los informes de tasación, que se producen generalmente de forma individual. Estos productos informativos sirven a dos tipos de destinatarios: el informe de tasación se realiza para quien lo solicitó o para aquél al que se dirige, por tanto un receptor conocido "a priori”. El catálogo de librería o de casa de subastas tiene como destinatario un comprador potencial. Ambos tipos de destinatario utilizan estos productos documentales para la toma de decisiones.

Scire. $10: 1$ (en.-jun. 2004) 101-120. 


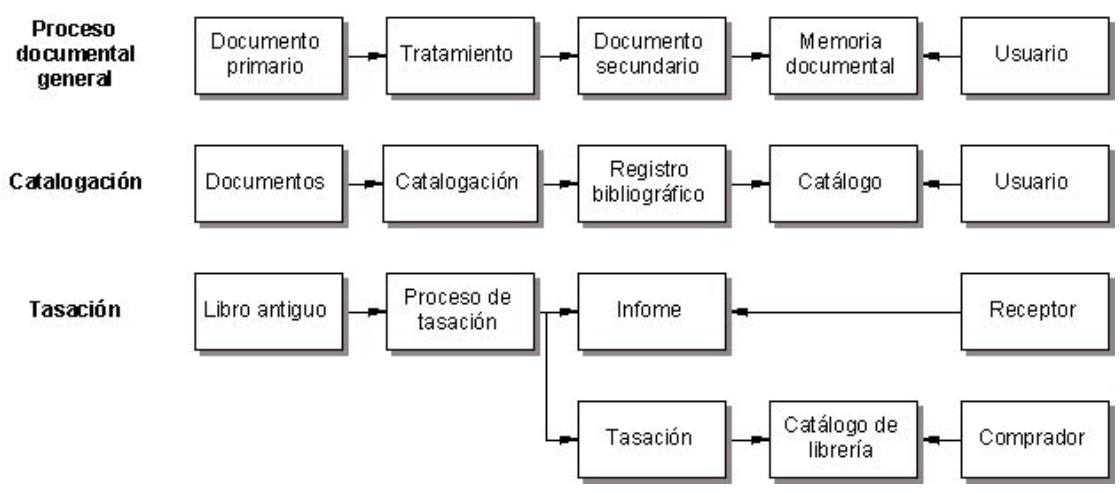

Fig. 2. La tasación como proceso documental frente a la catalogación

La tasación del libro es un proceso en el que la información constitutiva de un documento primario - un ejemplar - se expresa de forma sintética mediante un conjunto de procedimientos técnicos especializados de carácter analítico en otro documento de carácter secundario - tasación - cuyo fin es proporcionar una valoración - no sólo económica- del documento objeto de estudio. Como es conocido, estos procedimientos analítico-sintéticos se denominan en documentación tratamiento documental.

\section{Referencias}

Bowers, F. T. (2001). Principios de descripción bibliográfica. Madrid: Arco/Libros, 2001. Checa Cremades, J. L. (1999). El Libro Antiguo. Madrid: Acento, 1999.

Clavería Laguarda, C. (2002). Criterios objetivos y subjetivos de tasación: continental books y miseria. // Pedraza Gracia, M.J. (ed.). Tasación, valoración y comercio del libro antiguo (textos y materiales): Jaca, 2-6 de septiembre de 2002. Zaragoza: Prensas Universitarias de Zaragoza, 2002. 167-180.

Devaux, Y. (1988). L'univers de la bibliophilie. Paris: Pygmalion, 1988.

Dexeus Mallol, M. (1993). De la valoración y tasación de libros. // El Museo de Pontevedra: Homenaje a Antonio Odriozola. 46 (1993). 335-350.

Dexeus Mallol, M. (2001). Las instituciones públicas ante la oferta de libros y documentos de interés histórico. // II Simposium Archivos familiares: valoración y tasación. Santander: Asociación para la Defensa del Patrimonio Bibliográfico y Documental de Cantabria, 2001. 13-34.

Gallego, E.; Córdoba, I. (2002). Las subastas de libros: apuntes para no iniciados. // Pliegos de Bibliofilia. 17 (2002) 11-16. 
Huarte Morton, F. (1987). El libro, el bibliotecario y el lector de fondo antiguo en la biblioteca. // Homenaje a Justo García Morales: Miscelánea de estudios con motivo de su jubilación. Madrid: ANABAD, 1987. 305-332.

Le Menach, G. (1957). Initiation á la technique du livre et á la bibliophilie. Paris: Le Guide de Poche, 1957.

Mendoza Díaz-Maroto, F. (2002). La pasión por los libros: un acercamiento a la Bibliofilia. Madrid: Espasa, 2002.

Olaechea Labayen, J.B. (1987). Nueva visión de la rareza de los libros. // Homenaje a Justo García Morales: Miscelánea de estudios con motivo de su jubilación. Madrid: ANABAD, 1987. 471-489.

Pedraza Gracia, M. J. (1999). La bibliografía retrospectiva en la WWW: un nuevo horizonte para una ciencia clásica. // Scire. 5:2 (1999) 75-89.

Pedraza Gracia, M. J. (2002a). Concepto, estructura material y formal y descripción del libro antiguo. // Pedraza Gracia, M. J. (ed.). Tasación, valoración y comercio del libro antiguo (textos y materiales): Jaca, 2-6 de septiembre de 2002. Zaragoza: Prensas Universitarias de Zaragoza, 2002. 11- 48.

Pedraza Gracia, M. J. (2002b). Instrumentos de ayuda para la tasación del libro antiguo: descripción y uso. // Pedraza Gracia, M. J. (ed.). Tasación, valoración y comercio del libro antiguo (textos y materiales): Jaca, 2-6 de septiembre de 2002. Zaragoza: Prensas Universitarias de Zaragoza, 2002. 181- 205.

Pedraza Gracia, M. J. (2002c). El libro antiguo en la red o El contacto de los extremos. // Scire. 8:2 (2002) 71-90.

Pedraza Gracia, M. J. (2003a). Algunas reflexiones sobre la tasación del libro antiguo como actividad documental. // Anales de documentación. 6 (2002) 221- 239.

Pedraza Gracia, M. J. (2003b). Identificación, análisis y descripción de los elementos materiales del libro antiguo. // Pedraza Gracia, M. J. (ed.). Comercio y tasación del libro antiguo (textos y materiales): Jaca, 1-5 de septiembre de 2003. Zaragoza: Prensas Universitarias de Zaragoza, 2003. 11-38.

Pons León, J. F. (2001). La óptica del librero especializado ante las tasaciones documentales. // II Simposium Archivos familiares: valoración y tasación. Santander: Asociación para la Defensa del Patrimonio Bibliográfico y Documental de Cantabria, 2001. 51-73.

Rossi, M. (1994). Il libro antico dal XV al XIX secolo: analisi e applicazione della seconda edizione dell'ISBD(A). Firenze: Leo S. Olschki, 1994. 